\title{
N87-1034 7
}

DAYTIME LIDAR MEASUREMENTS OF TIDAL WINDS IN THE MESOSPHERIC SODIUM LAYER AT URBANA, ILLINOIS

K. H. Kwon, D. C. Senft, C. S. Gardner, D. G. Voelz and C. F. Sechrist, Jr.

Department of Electrical and Computer Engineering

University of Illinois at Urbana-Champaign

Urbana, Illinois 61801

F. L. Roesler

Department of Physics

University of Wisconsin

Madison, Wisconsin 53706

\section{SUMMARY}

For more than 15 years lidar systems have been used to study the chemistry and dynamics of the mesospheric sodium layer. Because the layer is an excellent tracer of atmospheric wave motions, sodium lidar has proven to be particularly useful for studying the influence of gravity waves and tides on mesospheric dynamics. These waves, which originate in the troposphere and stratosphere, propagate through the mesosphere and dissipate their energy near the mesopause making important contributions to the momentum and turbulence budget in this region of the atmosphere. Recently, the UIUC sodium lidar was modified for daytime operation so that wave phenomena and chemical effects could be monitored throughout the complete diurnal cycle. This paper describes the results of continuous 24 hour lidar observations of the sodium layer structure and presents measurements of the semidiurnal tidal winds.

The first daytime sodium lidar measurements were reported by Gibson and Sandford [1972] at Winkfield, UK $\left(51^{\circ} \mathrm{N}, 1^{\circ} \mathrm{W}\right)$. Their measurements were obtained on a total of 7 days in 1971 and 1972 and revealed no pronounced change in sodium abundance between day and night. Granier and Megie [1982] reported daytime observations at Haute Provence, France $\left(44^{\circ} \mathrm{N}, 6^{\circ} \mathrm{E}\right)$ which also showed no consistent diurnal or semidiurnal variations in the layer. The most extensive set of daytime lidar measurements was reported by Clemesha et al. [1982] and Batista et al. [1985]. Their data were obtained at Sao Paulo, Brazil $\left(23^{\circ} \mathrm{S}, 46^{\circ} \mathrm{W}\right)$ during 10 days in May 1981 and included one period of 100 hours of continuous measurements. Significant semidiurnal variations in the column abundance and centroid height were observed and attributed to the semidiurnal tide. The measured peak-to-peak abundance variation was approximately $30 \%$ and the peak-to-peak centroid displacement was approximately $2 \mathrm{~km}$. Tidal perturbations of the nocturnal sodium layer are often observed at Urbana $\left(40^{\circ} \mathrm{N}, 88^{\circ} \mathrm{W}\right)$ [Gardner et al., 1986] wher vertical wind velocities due to the semidiurnal tide of up to $30 \mathrm{cms}^{-1}$ with vertical wavelengths of the order of $50 \mathrm{~km}$ have been measured. 
During the late summer and early fall 1985, the UIUC lidar system was modified for daytime operation. The modifications were required to reduce the high background photocount level from the bright daytime sky. The $1.22 \mathrm{~m}$ diameter Fresnel lens telescope was replaced by a diffraction limited $0.35 \mathrm{~m}$ diameter astronomical telescope (Celestron 14). The planar field of view of the telescope was reduced to $0.7 \mathrm{mrad}$ and a pressure-tuned etalon filter was added to reduce the bandwidth to $33 \mathrm{pm}$ FWH. The laser divergence was also reduced to about $0.7 \mathrm{mrad}$ ( $F W\left(\mathrm{C}^{-2}\right.$ ) by expanding the beam by a factor of 22 .

The first daytime measurements were obtained at Urbana on 0ctober 5 , 1985. Continuous 24 hour measurements were first made on January 15 and 16 , 1986. Figure 1 is a summary of the profiles collected during these two days. The layer column abundance, centroid height and rms width are plotted versus time in Figure 2. Notice the strong semidiurnal oscillations in these parameters. The apundapce varied by almost a factor of 3 reaching a maxigym value of $2.5 \times 10^{10} \mathrm{~cm}^{-2}$ at 1545 LST and a minimum value of

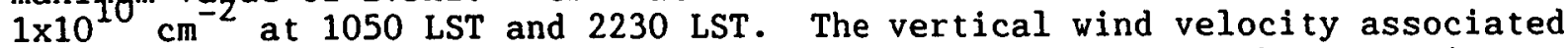
with these tidal perturbations can be inferred from the data by measuring the movement of the layer bottomside. The vertical wind velocity at $85 \mathrm{~km}$ altitude and the column abundance are plotted in Figure 3 . A strong semidiurnal oscillation in the wind velocity is clearly evident. The $30 \mathrm{cms}^{-1}$ wind amplitude is typical of the semidiurnal tide and is consistent with recent tidal models.

This work was supported in part by the National Science Foundation Grant ATM 85-11330.

\section{REPERENCES}

1. Batista, P. P., B. R. Clemesha, D. M. Simonich and V. W. J. H. Kirchhoff, "Tidal oscillations in the atmospheric sodium layer," J. Geophys. Res., 90 , p. 3881-3888, 1985 .

2. Clemesha, B. R., D. M. Simonich, P. P. Batista and V. W. J. H. Kirchhoff, "The diurnal variations of atmospheric sodium," J. Geophys. Res., 87, p. $181-186,1982$.

3. Gardner, C. S., D. G. Voelz, C. F. Sechrist, Jr. and A. C. Segal, "Lidar studies of the nighttime sodium layer over Urbana, Illinois. 1. Seasonal and nocturnal variations," Electro-0ptic Systems Laboratory, EOSL 86-001, University of Illinois (UILU-ENG-85-2547), January 1986.

4. Gibson, A. J. and M. C. W. Sandford, "Daytime laser radar measurements of the atmospheric sodium layer," Nature, 239, 509-511, 1972.

5. Granier, C. and G. Megie, "Daytime lidar measurements of the mesospheric sodium layer," Planet Space Sci., 30, 169-177, 1982. 
JANUARY $15-16,1986$
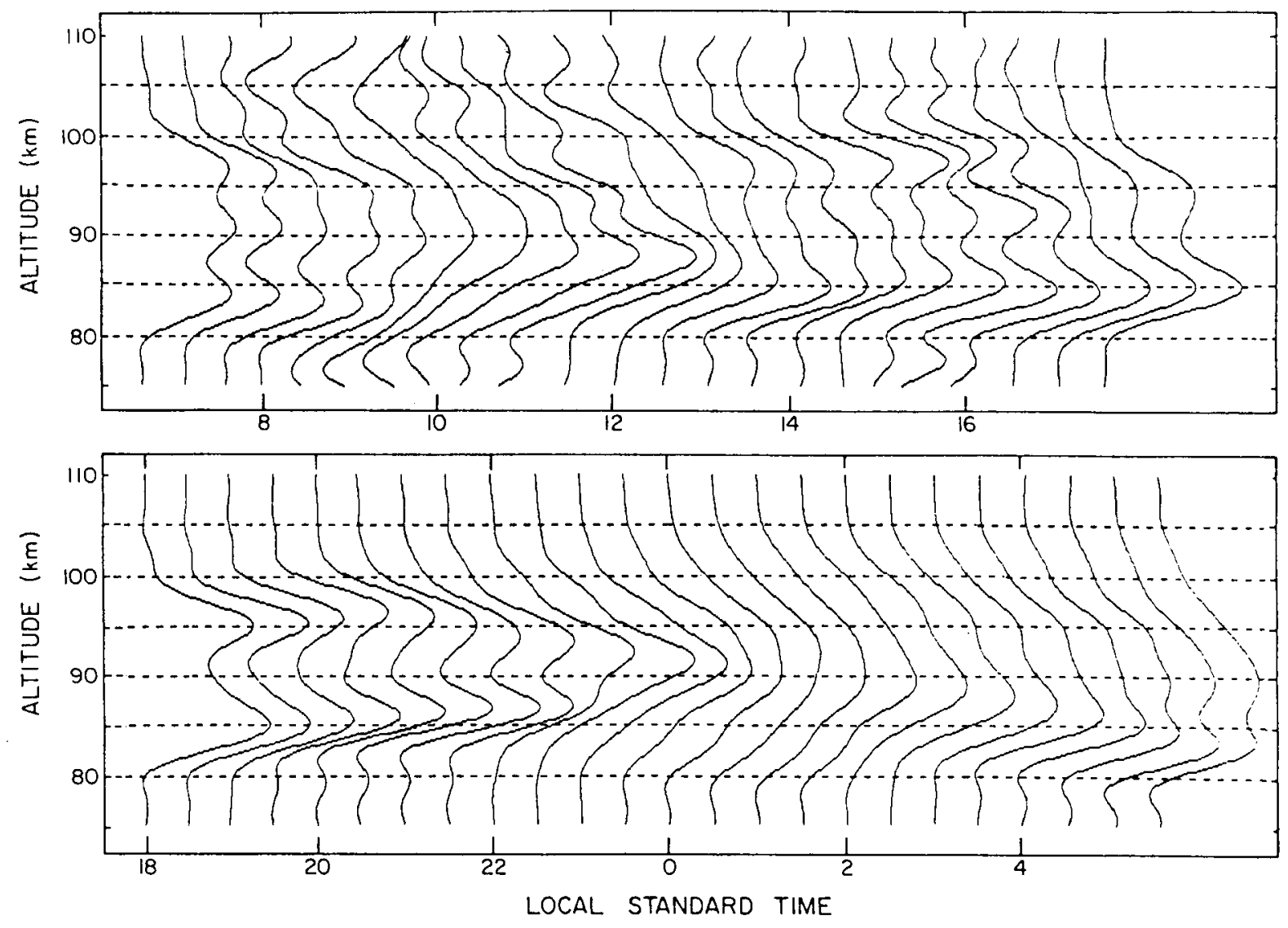

Figure 1. Na density profiles measured during the 24 hour period starting at 0600 LST on January 15, 1985 and ending at 0600 LST on January 16, 1985. The profiles are plotted at $30 \mathrm{~min}$ intervals and have been low-pass spatially filtered with a cutoff frequency
of $0.16 \mathrm{~km}^{-1}$. 


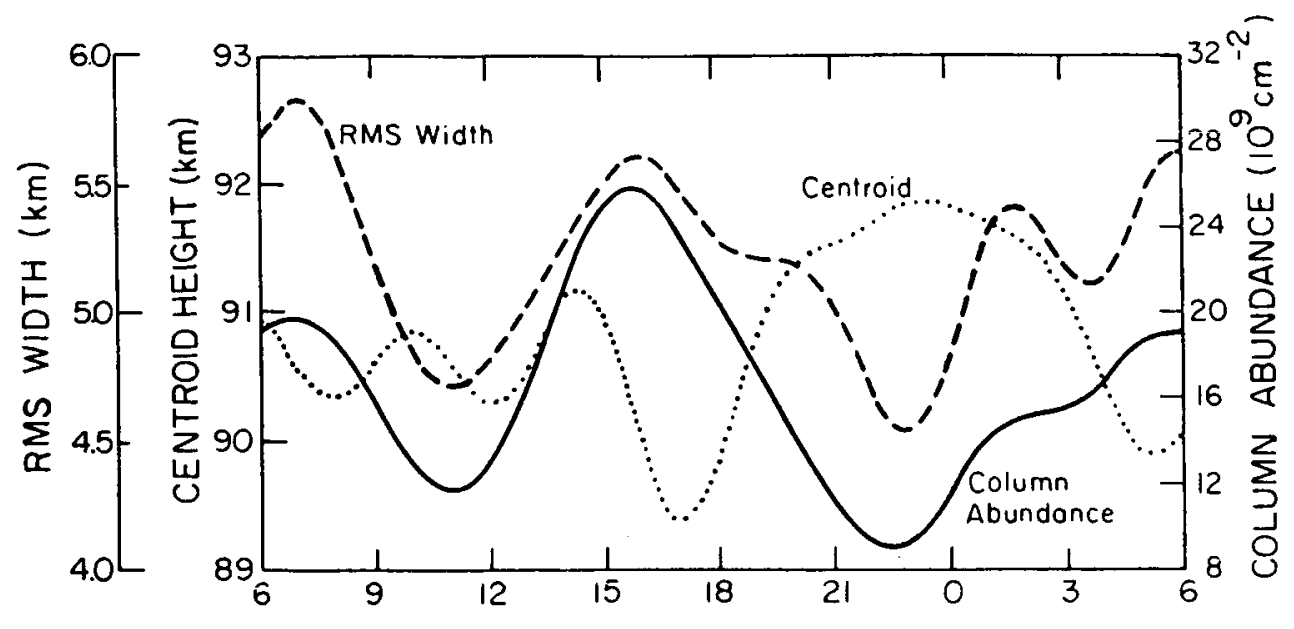

LOCAL STANDARD TIME

Figure 2. Temporal variations of the layer column abundance, centroid height and rms width measured during the $24 \mathrm{hr}$ period starting at 0600 LST on January 15, 1986. The data yere low-pass filtered with a spatial cutoff frequency of $0.05 \mathrm{~km}^{-1}$ and a temporal cutoff frequency of $0.25 \mathrm{hr}^{-1}$.

JANUARY $15-16 \quad 1986$

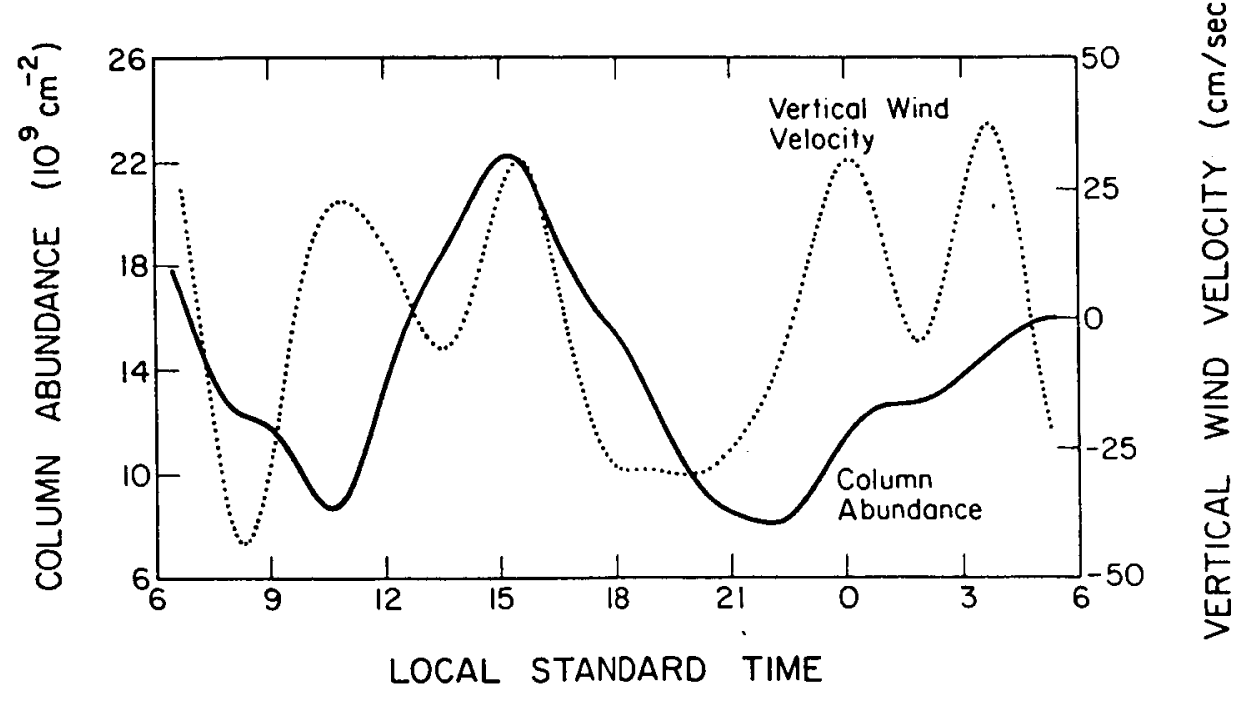

Figure 3. Comparison of the measured column abundance and vertical wind velocity (e $85 \mathrm{~km}$ altitude). To eliminate shorter wavelength gravity wave perturbations the density profiles were initially low-pass spatially and temporally filtered $y^{i}$ th respective frequency cutoffs of $0.05 \mathrm{~km}^{-1}$ and $0.33 \mathrm{hr}^{-1}$. The wind velocity was then determined from the displacement of the bottomside of the filtered profiles. 